\title{
Expiratory flow limitation during mechanical ventilation detected by the forced oscillation method
}

\author{
M. Vassiliou, R. Peslin, C. Saunier, C. Duvivier
}

Expiratory flow limitation during mechanical ventilation detected by the forced oscillation method. M. Vassiliou, R. Peslin, C. Saunier, C. Duvivier. (CERS Journals Ltd 1996. ABSTRACT: We have previously observed large phasic variations of respiratory mechanical impedance in chronic obstructive pulmonary disease (COPD) patients mechanically-ventilated for acute respiratory failure, and postulated that they were due to expiratory flow limitation (EFL). The aim of this study was to test that assumption experimentally and to assess the value of impedance for automatic and noninvasive detection of EFL during mechanical ventilation.

The study was performed: 1) in a mechanical analogue, including a flow-limiting element; and 2) in eight anaesthetized and paralysed rabbits, before and during histamine infusion. In both instances, EFL was obtained by lowering the expiratory pressure, using a computer-controlled ventilator; the absence of flow increase when expiratory pressure was further lowered was taken as evidence of EFL. Impedance was measured by applying $15 \mathrm{~Hz}$ oscillations at the airway opening. Its real (Re) and imaginary (Im) parts were measured separately during the inspiratory and the expiratory phases, and their differences were related to the mean inspiratory modulus.

With the analogue, EFL was accompanied by large decreases both of Re and Im during the expiratory phase. In the rabbits, phasic variations of Re were variable in sign and were not significantly different with and without EFL. In contrast, EFL systematically and specifically decreased Im during the expiratory phase. A threshold of $-50 \%$ provided a sensitivity of $96 \%$ and a specificity of $100 \%$ for detecting EFL. The observed phasic variations may be explained by airway wall shunt properties.

The study suggests that a large decrease of the imaginary part of impedance during the expiratory phase is a sensitive and specific index of expiratory flow limitation during artificial ventilation.

Eur Respir J., 1996, 9, 779-786.
Unité 14 de Physiopathologie Respiratoire, Institut National de la Santé et de la Recherche Médicale, Université H. Poincaré Nancy 1, Vandoeuvre-les-Nancy, France.

Correspondence: R. Peslin

Unité 14 INSERM

Physiopathologie Respiratoire C.O. $\mathrm{n}^{\circ} 10$

54511 Vandoeuvre-les-Nancy cedex

France

Keywords: Artificial ventilation

expiratory flow limitation

monitoring

respiratory impedance

respiratory mechanics

Received: July 191995

Accepted after revision November 71995
Expiratory flow limitation (EFL) is a frequent occurrence during artificial ventilation of patients with severe airway obstruction [1-6]. It results in dynamic hyperinflation and increased mean alveolar pressure, with adverse effects on pulmonary circulation [1]; it has also been shown to increase the work of breathing necessary to trigger the ventilator $[7,8]$ when the patients are ventilated in the assisted mode. Finally, it is likely that EFL, unless it occurs in the trachea, is unevenly distributed inside the lung and enhances maldistribution of the inspired gas. Applying a positive end-expiratory pressure (PEEP) has been shown to suppress EFL [5, 6], totally or partially, and to decrease at least some of the above-mentioned complications [8,9].

Recognition of EFL during artificial ventilation is, therefore, of much practical interest. This may be achieved using a number of methods. The simplest is to observe the shape of the flow-volume or of the flow-time curve: the occurrence of a sharp flow transient at the very beginning of the expiratory phase is highly suggestive of EFL [2]; however, such transients may be missing, and the shape of the flow signal may be similarly altered in other situations (inhomogeneous lung emptying or strong nonlinearity of the pressure-volume curve) [10]. The reference method consists in observing the flow signal at a given lung volume whilst varying the expiratory pressure; the observation of an unchanged expiratory flow at two levels of pressure demonstrates flow limitation. A number of variants of this method have been described: suppressing or decreasing a pre-existing PEEP [2, 9]; applying a negative expiratory pressure [10]; increasing the resistance of the expiratory circuit of the ventilator $[2,11]$; lowering or shunting the resistance of the expiratory circuit [10]. A characteristic common to all of these variants is that they require some intervention on the ventilator settings or on the expiratory circuit. They are then not very suitable for a fully automatized detection of EFL during artificial ventilation.

The object of this study was to test a new method of detecting EFL which would not require any intervention on the ventilator or on the breathing conditions, and would be suitable for continuous monitoring of mechanicallyventilated patients. It is based on our previous observation of large phasic variations in respiratory impedance $\left(Z_{\mathrm{rs}}\right)$, as measured by forced oscillations, in patients likely to present EFL [12]. More specifically, EFL would provoke 
a sudden and important decrease of the imaginary part of $\mathrm{Zrs}$ (Im) during the expiratory phase. The sensitivity and the specificity of the method was evaluated both on mechanical analogues of the respiratory system and in artificially-ventilated rabbits. In both instances, EFL was produced by lowering the expiratory pressure, and the absence of flow variation when the expiratory pressure was further decreased was taken as a reference. The study confirms our previous observations and demonstrates the value of impedance measurements to detect EFL during mechanical ventilation.

\section{Material and methods}

\section{Ventilator and measuring set-up}

In order to manipulate at will the expiratory pressure (EP), we used a computer-controlled ventilator built in the laboratory [13]. Briefly, the system included an inspiratory and an expiratory rubber bellows, each driven by a linear motor supplied by a power amplifier (fig. 1). The motion of the bellows, and the three-way solenoid valves connecting them to the airway were controlled by a microcomputer (Dell 466/Le) equipped with a 12-bit analogue-to-digital/digital-to-analogue (AD/DA) conversion board (PCLab, Digimétrie). The computer program made it possible to impose instantaneous flow or pressure during both phases. This was achieved using a proportional-integral algorithm, which minimized the instantaneous difference between the target inspiratory or expiratory pressure or flow and those measured at the airway opening. Flow $\left(V^{\prime}\right)$ was measured with a Fleisch No. 00 pneumotachograph connected to a piezoresistive differential pressure transducer (Honeywell 176/14), and airway opening pressure $(P \mathrm{ao})$ with a similar transducer. The responses of the two transducers were matched for amplitude $( \pm 2 \%)$ and phase $\left( \pm 2^{\circ}\right)$ up to $15 \mathrm{~Hz}$. $V^{\prime}$ was calibrated by the integral method using a $30 \mathrm{~mL}$ syringe, and $P$ ao with a slanted fluid manometer. The signals were lowpass filtered at $30 \mathrm{~Hz}$ and were sampled at a rate of 180 $\mathrm{Hz}$. The flow signal was digitally linearized [14]. In this study, a constant flow target was set during the inspiratory phase, and a constant pressure target during the expiratory phase. The expiratory pressure $( \pm 20 \mathrm{hPa})$ could be modified at will from the computer keyboard, without interrupting the ventilation. Also, to test for the presence of EFL, it was possible to programme the system to deliver, at a preset frequency, a respiratory cycle with a $5 \mathrm{hPa}$ more negative expiratory pressure. Finally, the computer program included a procedure for on-line computation of respiratory resistance $(R \mathrm{rs})$ and elastance $(E$ rs $)$ by fitting the signals to the usual first order model by multiple linear regression [15]:

$$
P \text { ao }=P 0+E \mathrm{rs} \cdot V+R \mathrm{rs} \cdot V^{\prime}
$$

where $V$ is the volume, obtained by digital integration of $V^{\prime}$, and $P 0$ is the elastic recoil pressure when $V=0$.

\section{Respiratory impedance measurements}

In addition to the respiratory signals, the system could deliver, through a power amplifier, a $15 \mathrm{~Hz}$ sinusoidal signal to a $30 \mathrm{~W}$ horn driver-type loudspeaker (Bouyer, Type 2R409) connected to the inspiratory line (fig. 1). This type of loudspeaker was used because it had a low compliance $\left(0.1 \mathrm{~mL} \cdot \mathrm{hPa}^{-1}\right)$ and could sustain the $10-30$

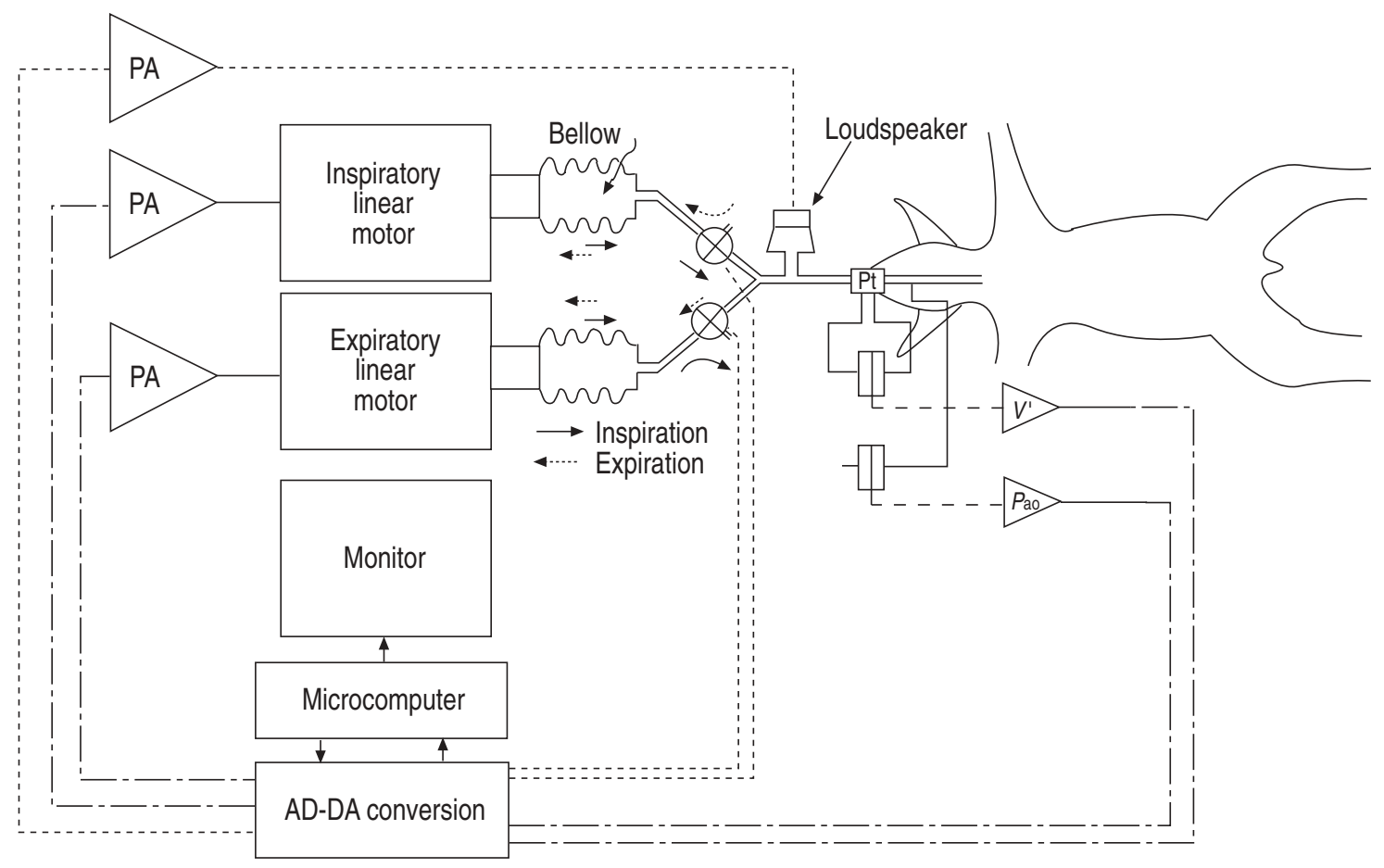

Fig. 1. - Computer-controlled respirator and experimental set-up. PA: power amplifier; Pt: pneumotachograph; AD-DA: analogue-to-digital/digital-to-analogue; $-\otimes \ldots$ : solenoid valve; $\_-$: amplifier; $V^{\prime}$ : flow; $P$ ao: airway opening pressure. 
$\mathrm{hPa}$ pressure swings generated by the ventilator. The corresponding pressure oscillations at the airway opening had an amplitude of 1-3 hPa peak-to-peak. For the measurements, the pressure and flow signals, digitized at a rate of $180 \mathrm{~Hz}$ (12 points per oscillation cycle), were recorded and stored for periods of $7.2 \mathrm{~s}$ (six respiratory cycles). Flow was corrected in the time domain for the $2.2 \mathrm{~ms}$ time constant of the pneumotachograph [16]. The real $(\mathrm{Re})$ and imaginary $(\mathrm{Im})$ parts of $\mathrm{Zrs}$ at $15 \mathrm{~Hz}$ were then computed by Fourier analysis of $P$ ao and $V^{\prime}$ [17, 18], after filtering out the low-frequency breathing components of the signals [19]. The computation was made separately for each oscillation cycle, so that the analysis provided 15 values of Re and Im for each second of measurement (18 values per respiratory cycle). The mean values of $\mathrm{Re}$ and Im were computed separately during the inspiratory and the expiratory phases, after excluding the outlying values observed during fast respiratory flow transients. Their difference (D) was related to the mean value of the impedance modulus during the inspiratory phase $\left(\mid \mathrm{Zinspl}=\left(\operatorname{Re}, \text { insp }^{2}+\operatorname{Im}, \text { insp }^{2}\right)^{1 / 2}\right)$ :

$$
\begin{aligned}
& \mathrm{D}(\mathrm{Re})=(\operatorname{Re}, \exp -\mathrm{Re}, \text { insp }) / \mid Z \text { inspl } \\
& \mathrm{D}(\operatorname{Im})=(\operatorname{Im}, \exp -\mathrm{Im}, \text { insp }) / \mid Z \text { inspl }
\end{aligned}
$$

\section{Measurements on mechanical analogues}

Measurements were first performed on two simple mechanical analogues of the respiratory system. Analogue A did not include any mechanical element which could be responsible for flow limitation; it was made of a glass bottle of $1.1 \mathrm{~L}$ (elastance of $1,260 \mathrm{hPa} \cdot \mathrm{L}^{-1}$ for adiabatic compression), in series with a resistance of 120 $\mathrm{hPa} \cdot \mathrm{s} \cdot \mathrm{L}^{-1}$, made of porous material (range of linearity $\left.\pm 0.1 \mathrm{~L} \cdot \mathrm{s}^{-1}\right)$. Analogue B included, in addition, a flat thinwalled $(0.9 \mathrm{~mm})$ rubber tube (Burnet Distribution, ref. 305402, Le Plessis Robinson) placed in series between analogue $\mathrm{A}$ and the ventilator. The tube was $3 \mathrm{~cm}$ long, had a perimeter of $36 \mathrm{~mm}$, and offered a negligible resistance to flow when its transmural pressure was positive. Its pressure-flow characteristics are shown in figure 2.

\section{Measurements in rabbits}

The experimental part of the study was performed in eight New Zealand rabbits with a body weight of 2.1-2.4 $\mathrm{kg}$. The animals were anaesthetized with sodium thiopental (15-20 mg. $\mathrm{kg}^{-1} i . v$., and additional doses as needed during the study) and tracheotomized. They were connected to the ventilator described above and ventilated during the whole study with a tidal volume of $25 \mathrm{~mL}$, an inspiratory/total time ratio of 0.4 , and a frequency of 50 cycles $\cdot \mathrm{min}^{-1}$. After connection to the ventilator, they were paralysed with vecuronium bromide $(0.8 \mathrm{mg}$, followed by continuous infusion of $0.4 \mathrm{mg} \cdot \mathrm{h}^{-1}$ ). After control measurements (see protocol below), the animals were administered histamine in to the left jugular vein (initial dose of $800 \mu \mathrm{g} \cdot \mathrm{kg}^{-1}$, followed by a continuous infusion at $4,000 \mu \mathrm{g} \cdot \mathrm{kg}^{-1} \cdot \mathrm{h}^{-1}$ ), and the measurements were repeated as soon as the resistance and elastance had reached a plateau.

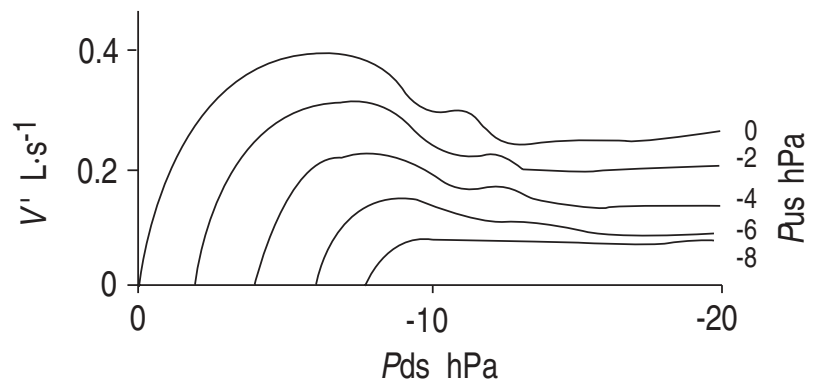

Fig. 2. - Pressure-flow characteristics of the flow-limiting element used in analogue $\mathrm{B}$. The curves were obtained by lowering the downstream pressure $(P \mathrm{ds})$, whilst keeping the upstream pressure $(P \mathrm{us})$ constant. $V^{\prime}$ : flow.

\section{Protocol}

In both analogues and rabbits each series of measurements included the following sequence: 1) the EP was set to the desired level; 2) the system was set to impose a respiratory cycle with an EP $5 \mathrm{hPa}$ below the required level every five breaths; respiratory cycles with the more negative EP are referred to below as NEP cycles; the flow-volume curves were displayed on-line so that the presence or absence of EFL could already be assessed visually by comparing NEP cycles to the others; six respiratory cycles, which included at least one NEP cycle, were recorded for off-line analysis; 3) NEP cycles were suppressed, and the system was set to deliver the $15 \mathrm{~Hz}$
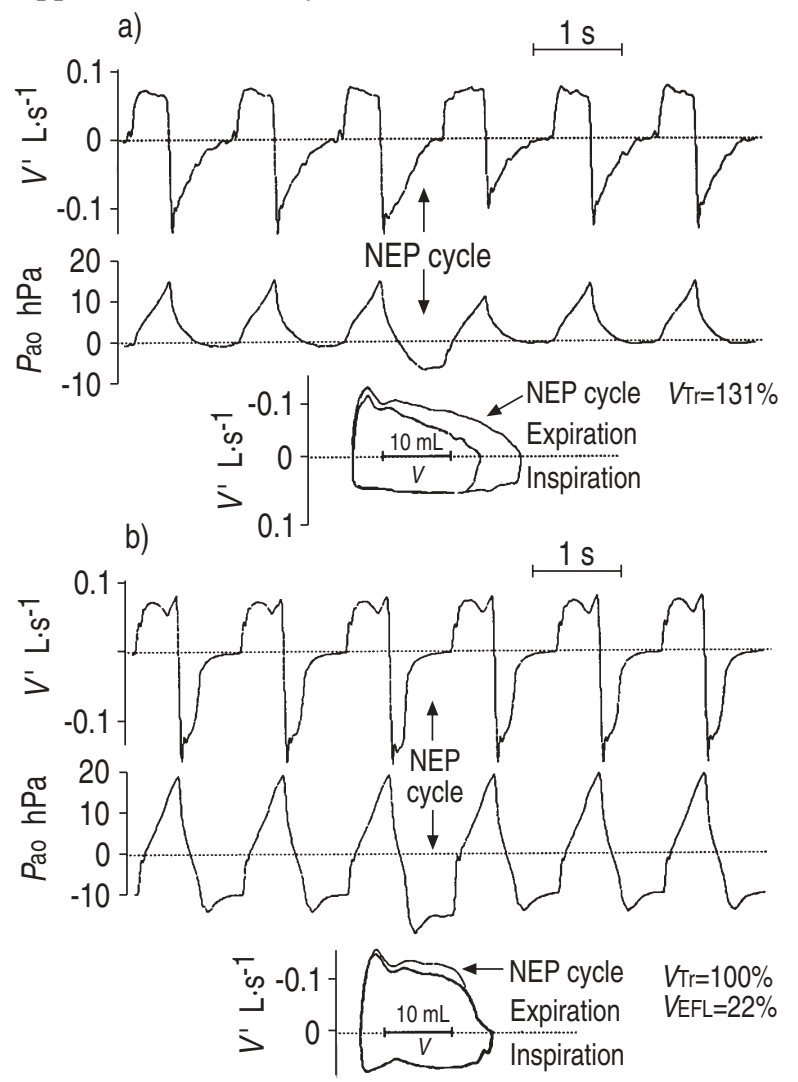

Fig. 3. - Examples of records used to recognize expiratory flow limitation (EFL). The records include normal respiratory cycles and a cycle with a more negative EP (NEP cycle). a) No EFL; expiratory flow increases during the NEP cycle (rabbit No. 8, EP=0); b) EFL during the last $22 \%$ of the expiratory phase (rabbit No. 8, EP=-10 hPa). $V$ Tr: tidal volume ratio; VEFL: volume at expiratory flow limitation. For further abbreviations see legend to figure 1 . 
forced oscillations; 4) six respiratory cycles were recorded for off-line measurement of respiratory impedance, as described above. Step 4 was repeated 2-3 times, consecutively; the data from repeated measurements were almost identical and were averaged. With the analogues, measurements were performed with EPs of $+5,0,-5$, 8 and $-10 \mathrm{hPa}$. In the rabbits, measurements were performed both before and during histamine infusion with EPs of $0,-5,-8$ and $-10 \mathrm{hPa}$. Before each measurement, the EP was set for 1-2 min to a positive value (about 5 $\mathrm{hPa}$ ) in order to standardize the volume history, and, if necessary, reopen closed airways.

\section{Recognition of flow limitation}

The records containing NEP cycles were reanalysed off-line to assess whether EFL was present; examples are shown in figure 3. The flow was considered limited if the flow-volume curves of the NEP cycle and of the preceding respiratory cycle came into contact at some point after the peak expiratory flow. When this was the case, the volume at which it occurred (VEFL) was measured and expressed as a percentage of the normal $V \mathrm{~T}$. The VTs of the NEP and of the preceding cycles were also measured, and their ratio (VTr) computed.

\section{Results}

\section{Mechanical analogues}

Examples of records obtained with analogues $\mathrm{A}$ and B during forced oscillation measurements are shown in figure 4. Figure 4 also shows the values of Re and Im corresponding to each oscillation cycle. It can be seen that impedance varied little during the respiratory cycle when expiration was not flow-limited (analogue A). In contrast, with analogue $\mathrm{B}$ at an $\mathrm{EP}$ of $-10 \mathrm{hPa}$, expiration was flow-limited ( $V \operatorname{Tr}$ of $101 \%$ ) and both Re and Im exhibited strong phasic variations. The data obtained with the two analogues at different expiratory pressures are shown in table 1 . With analogue A, EFL never occurred and the expired $V$ T was $17-23 \%$ larger during the NEP cycles. The change in Re from inspiration to expiration represented at most $4.7 \%$ and that of $\mathrm{Im}-7.3 \%$ of the inspiratory impedance modulus; these slight variations were not related to the level of EP. With analogue $\mathrm{B}$, EFL was not present when the EP was positive or nil, and the corresponding phasic variations of $\mathrm{Re}$ and $\mathrm{Im}$ were just a little larger than with analogue A. At pressures of $-5,-8$ and $-10 \mathrm{hPa}$, EFL was always present, as shown by a $V \operatorname{Tr}$ of $96-101 \%$, and occurred in the middle of the expiratory phase $(V \mathrm{EFL}=47-55 \%)$. EFL was always accompanied by a very large decrease both of Re and Im, which became strongly negative. The magnitude of the variations was not related to the level of pressure.

\section{Rabbits}

Records with and without flow limitation in a representative rabbit are shown in figure 5, along with the corresponding values of $\mathrm{Re}$ and $\mathrm{Im}$. As seen with the

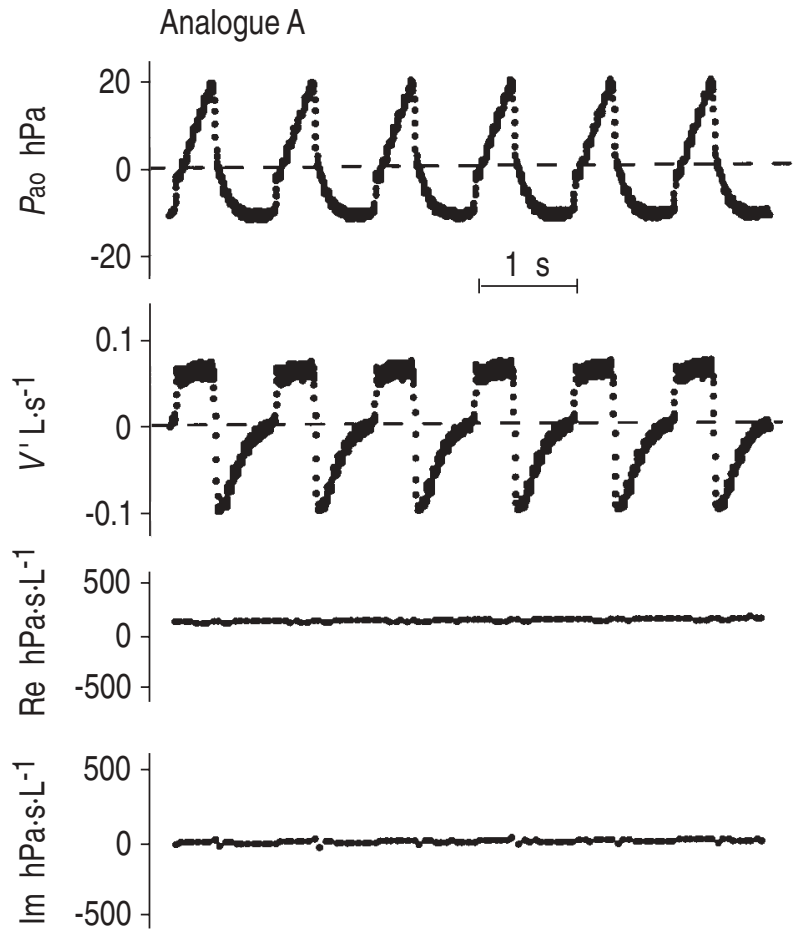

Analogue B

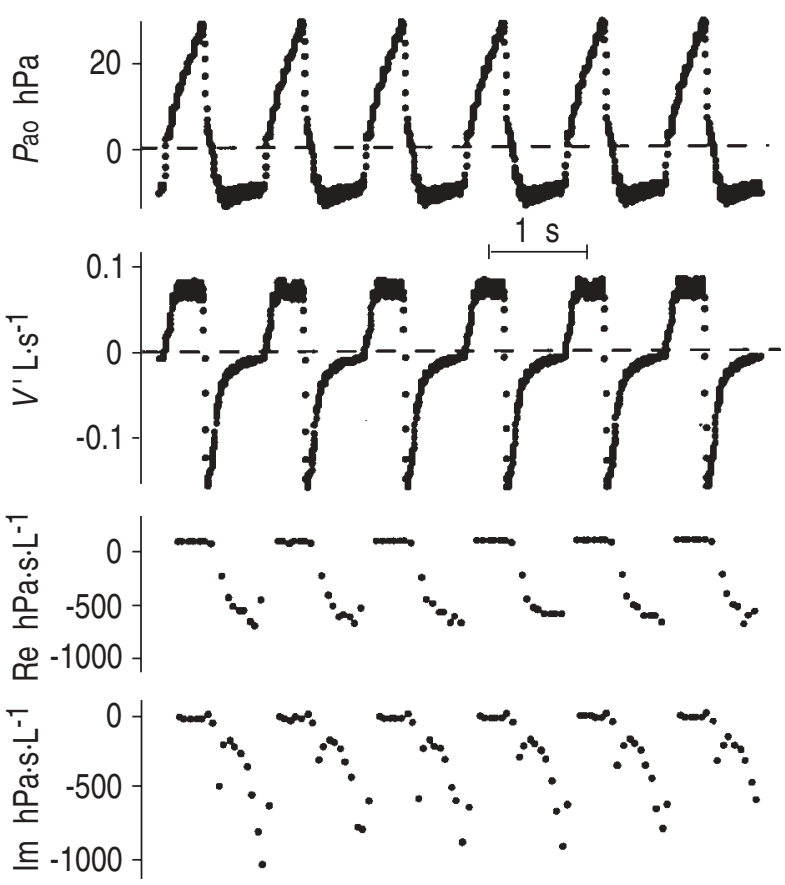

Fig. 4. - Examples of airway opening pressure $(P$ ao $)$ and flow $\left(V^{\prime}\right)$ records obtained with the mechanical analogues during forced oscillations measurements, together with values of real (Re) and imaginary (Im) parts of impedance. Strong phasic variations of Re and Im are seen with analogue B, which includes a flow limiting element (fig. 2).

analogue, Re and Im varied little in the absence of EFL, but underwent large phasic variations when it was present. The results obtained at the different expiratory pressures in the eight rabbits are presented in table 2 . Both before and after histamine, EFL only occurred when the EP was negative. In control conditions, it was 
Table 1. - Volume data and impedance changes in the two mechanical analogues

\begin{tabular}{|c|c|c|c|c|c|c|c|c|}
\hline \multirow[b]{2}{*}{$\begin{array}{l}\mathrm{PE} \\
\mathrm{hPa}\end{array}$} & \multicolumn{4}{|c|}{ Analogue A } & \multicolumn{4}{|c|}{ Analogue B } \\
\hline & $\begin{array}{c}V \operatorname{Tr} \\
\%\end{array}$ & $\begin{array}{c}\text { VEFL } \\
\%\end{array}$ & $\begin{array}{c}\mathrm{D}(\mathrm{Re}) \\
\%\end{array}$ & $\begin{array}{c}\mathrm{D}(\mathrm{Im}) \\
\%\end{array}$ & $\begin{array}{l}V \operatorname{Tr} \\
\%\end{array}$ & $\begin{array}{c}V \text { EFL } \\
\%\end{array}$ & $\begin{array}{c}\mathrm{D}(\mathrm{Re}) \\
\%\end{array}$ & $\begin{array}{c}\mathrm{D}(\operatorname{Im}) \\
\%\end{array}$ \\
\hline+5 & 117 & - & 2.8 & -6.2 & 118 & - & 8.3 & -14.5 \\
\hline 0 & 121 & - & 4.7 & -7.3 & 105 & - & -3.0 & -16.0 \\
\hline-5 & 122 & - & 2.0 & -6.7 & 96 & 47 & -319.5 & -219.1 \\
\hline-8 & 123 & - & 2.9 & -7.0 & 99 & 53 & -239.8 & -269.4 \\
\hline-10 & 121 & - & 2.2 & -7.3 & 101 & 55 & -242.7 & -169.4 \\
\hline
\end{tabular}

PE: expiratory pressure; $V$ Tr: tidal volume ratio; $V \mathrm{EFL}$ : volume of expiratory flow limitation (see text); $\mathrm{D}(\mathrm{Re})$, $\mathrm{D}(\mathrm{Im})$ : phasic variations of real and imaginary part of impedance, respectively (Equations 1 and 2).

Table 2. - Volume data and impedance changes in rabbits

\begin{tabular}{|c|c|c|c|c|c|c|c|c|}
\hline \multirow[b]{2}{*}{$\begin{array}{l}\mathrm{PE} \\
\mathrm{hPa}\end{array}$} & \multicolumn{4}{|c|}{ Before histamine } & \multicolumn{4}{|c|}{ During histamine infusion } \\
\hline & $\begin{array}{r}V \operatorname{Tr} \\
\%\end{array}$ & $\begin{array}{c}V \mathrm{EFL} \\
\%\end{array}$ & $\begin{array}{c}\mathrm{D}(\mathrm{Re}) \\
\%\end{array}$ & $\begin{array}{c}\mathrm{D}(\mathrm{Im}) \\
\%\end{array}$ & $\begin{array}{c}V \operatorname{Tr} \\
\%\end{array}$ & $\begin{array}{c}V \text { EFL } \\
\%\end{array}$ & $\begin{array}{c}\mathrm{D}(\mathrm{Re}) \\
\%\end{array}$ & $\underset{\%}{\mathrm{D}(\mathrm{Im})}$ \\
\hline \multicolumn{9}{|c|}{ Rabbit No. 1} \\
\hline 0 & 133 & - & 5.0 & -18.0 & 134 & - & -14.5 & -3.0 \\
\hline-5 & 107 & 16 & 73.0 & -128.0 & 101 & 34 & 56.5 & -111.0 \\
\hline-8 & 101 & 20 & 6.0 & -71.0 & 103 & 44 & -31.9 & -381.9 \\
\hline-11 & 98 & 19 & -39.0 & -73.5 & 101 & 40 & -43.4 & -292.6 \\
\hline \multicolumn{9}{|c|}{ Rabbit No. 2} \\
\hline 0 & 131 & - & -12.9 & -22.3 & 121 & - & -25.0 & -5.0 \\
\hline-5 & 112 & - & 16.9 & -39.4 & 99 & 44 & 43.0 & -155.0 \\
\hline-8 & 101 & 18 & 24.3 & -67.3 & 106 & 19 & 10.0 & -200.0 \\
\hline-10 & 98 & 20 & 7.0 & -190.0 & 104 & 25 & 20.0 & -364.0 \\
\hline \multicolumn{9}{|c|}{ Rabbit No. 3} \\
\hline 0 & 130 & - & -12.8 & -24.3 & 117 & - & 2.0 & -12.0 \\
\hline-5 & 106 & 11 & 0.2 & -60.0 & 101 & 52 & 21.0 & -166.0 \\
\hline-8 & 101 & 23 & -26.0 & -110.0 & 100 & 47 & -20.0 & -270.0 \\
\hline-10 & 103 & 23 & -19.0 & -396.0 & 102 & 44 & -29.0 & -435.0 \\
\hline \multicolumn{9}{|c|}{ Rabbit No. 4} \\
\hline 0 & 134 & - & -5.0 & -17.0 & 132 & - & -5.0 & -13.0 \\
\hline-5 & 101 & 20 & 39.0 & -74.0 & 99 & 55 & 76.0 & -245.0 \\
\hline-8 & 98 & 31 & 87.0 & -264.0 & 106 & 49 & 21.0 & -363.0 \\
\hline-10 & 102 & 20 & -18.0 & -388.0 & 100 & 37 & -18.0 & -476.0 \\
\hline \multicolumn{9}{|c|}{ Rabbit No. 5} \\
\hline 0 & 128 & - & 4.0 & -4.0 & 134 & - & -1.2 & -15.0 \\
\hline-5 & 111 & 10 & 35.0 & -22.4 & 100 & 67 & 96.0 & -291.0 \\
\hline-8 & 102 & 17 & 46.0 & -95.0 & 102 & 67 & -44.0 & -548.0 \\
\hline-10 & 102 & 21 & 3.0 & -227.0 & 99 & 49 & -187.0 & -722.0 \\
\hline \multicolumn{9}{|c|}{ Rabbit No. 6} \\
\hline 0 & 128 & - & -7.0 & -22.0 & 113 & - & -2.0 & -13.0 \\
\hline-5 & 106 & - & 9.0 & -7.0 & 102 & 48 & 76.0 & -276.0 \\
\hline-8 & 101 & 12 & 5.0 & -72.0 & 103 & 41 & 29.0 & -365.0 \\
\hline-10 & 103 & 17 & 47.0 & -74.0 & 99 & 4.1 & -33.0 & -512.0 \\
\hline \multicolumn{9}{|c|}{ Rabbit No. 7} \\
\hline 0 & 132 & - & -6.0 & -14.0 & 123 & - & -9.0 & -15.0 \\
\hline-5 & 102 & 10 & 20.0 & -13.0 & 105 & 62 & 46.0 & -212.0 \\
\hline-8 & 101 & 22 & -5.0 & -112.0 & 100 & 51 & -54.0 & -446.0 \\
\hline-10 & 96 & 25 & 44.0 & -196.0 & 100 & 46 & -74.0 & -524.0 \\
\hline \multicolumn{9}{|c|}{ Rabbit No. 8} \\
\hline 0 & 131 & - & 17.0 & -23.0 & 136 & - & 10.0 & -18.0 \\
\hline-5 & 110 & - & 6.0 & -24.0 & 106 & 42 & 44.0 & -229.0 \\
\hline 08 & 102 & 10 & 22.0 & -77.0 & 102 & 28 & -18.0 & -231.0 \\
\hline-10 & 100 & 17 & 8.0 & -156.0 & 99 & 22 & -35.0 & -110.0 \\
\hline
\end{tabular}

For abbreviations see legend to table 1. 
a)
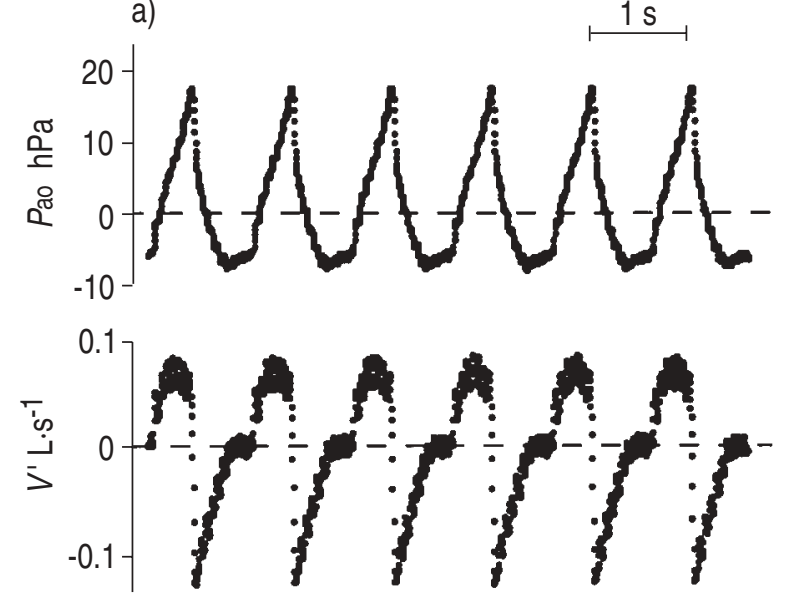

辛

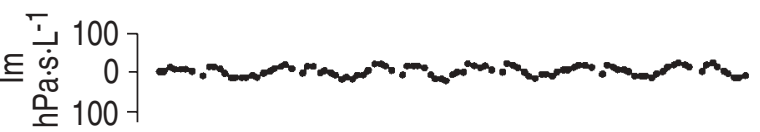

b)
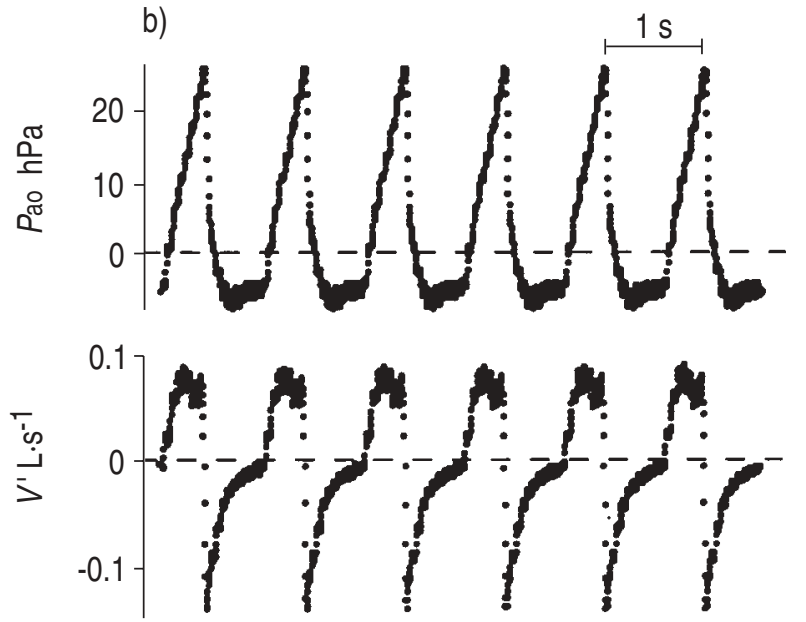

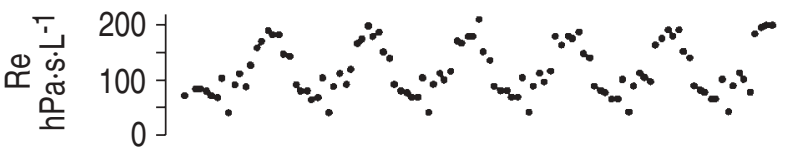

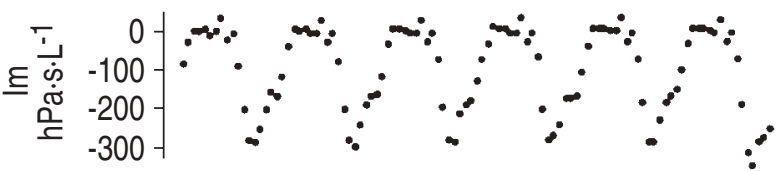

Fig. 5. - Examples of airway opening pressure $(P$ ao $)$ and flow $\left(V^{\prime}\right)$ records during forced oscillation measurements in rabbits. Rabbit No. $8, \mathrm{PE}=-5 \mathrm{hPa}$ : a) before (no EFL); and b) during (EFL) histamine infusion. EFL provokes a sharp decrease of Im during expiration, but in this example an increase of Re. EFL: expiratory flow limitation; Im: imaginary part of impedance; Re: real part of impedance. For further abbreviations see legend to figure 1 .

present at an $\mathrm{EP}$ of $-5 \mathrm{hPa}$ in five rabbits, and at an $\mathrm{EP}$ of $-8 \mathrm{hPa}$ in all of them. After histamine, it was always present at an EP of $-5 \mathrm{hPa}$. VEFL varied from 10 to $67 \%$ and was systematically larger during histamine infusion. The data are summarized in figure 6 , which shows the
No EFL

EFL

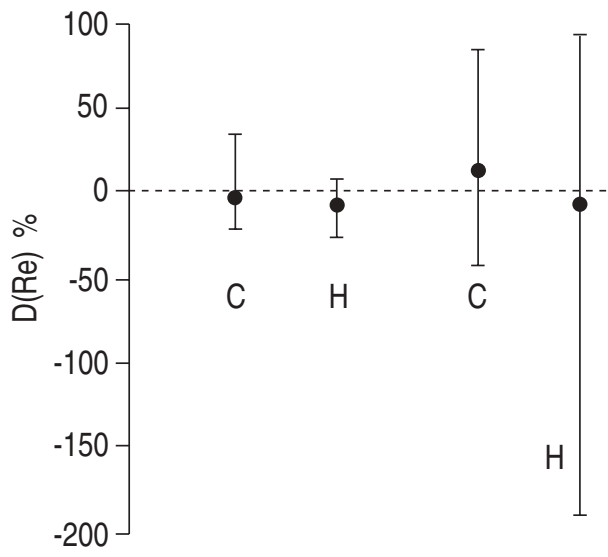

No EFL

EFL

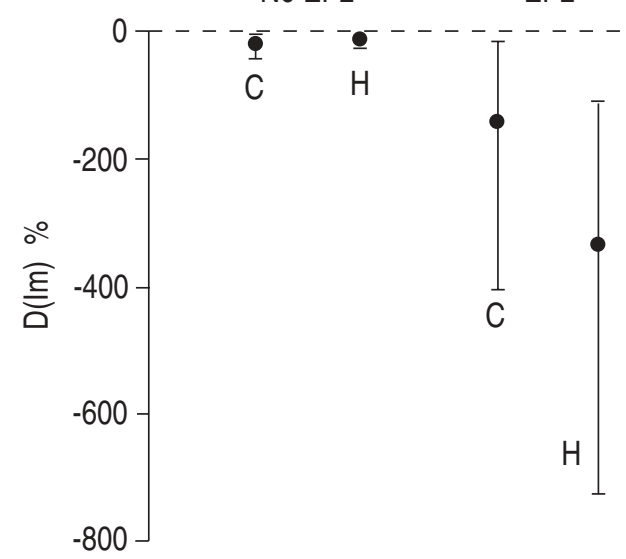

Fig. 6. - Phasic variations in the real (DRel) and imaginary (D(Im)) part of impedance in the presence and absence of expiratory flow limitation (EFL) in rabbits. C: control; H: histamine infusion. Values are presented as mean and range.

ranges and mean values of $\mathrm{D}(\mathrm{Re})$ and $\mathrm{D}(\mathrm{Im})$ with and without EFL. It may be seen that both before and during histamine, the range of $\mathrm{D}(\mathrm{Re})$ during EFL exceeded at both ends that observed without EFL. In contrast, the lowest value of $\mathrm{D}(\mathrm{Im})$ without EFL $(-18 \%)$ was just a little lower than the largest value with EFL (-13\%). Taking a value of $-50 \%$ as a threshold for $\mathrm{D}(\mathrm{Im})$ provided a sensitivity of $96 \%$ and a specificity of $100 \%$ for detecting EFL. The two false negatives both had a very late $\operatorname{EFL}(V \mathrm{EFL}=10 \%)$.

\section{Discussion}

In a previous study, we observed large phasic variations of respiratory mechanical impedance in artificiallyventilated COPD patients, and suggested that they could be related to EFL [12]. The above results confirm that interpretation and demonstrate that EFL is responsible for a systematic and marked decrease of Im during the expiratory phase; in contrast the variations of Re are not systematic and are variable in sign.

These facts may be interpreted with a variant of the two-compartment model proposed by MEAD [20]. The rationale of that model (fig. 7) is that airways are not simply conduits, but are compliant structures, which may expand and shunt some of the inspired gas. One of the compartments in the model represents the peripheral 


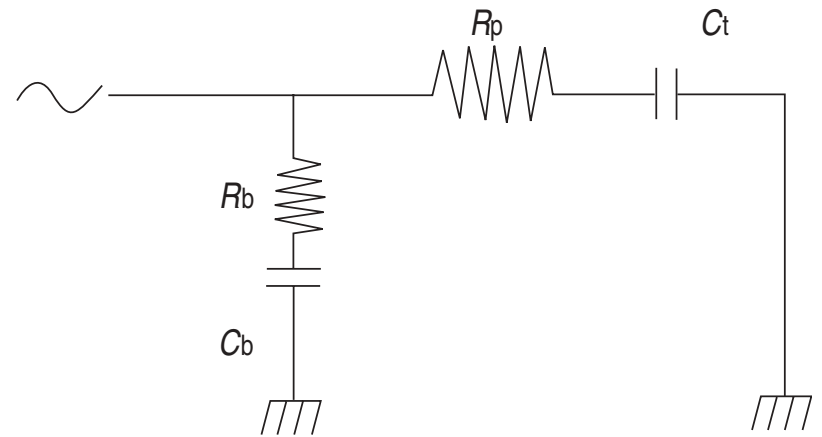

Fig. 7. - Two-compartment model representing airway wall resistance $(R \mathrm{~b})$ and compliance $(C \mathrm{~b})$ in parallel with peripheral resistance $\left(R_{\mathrm{p}}\right)$ and tissue compliance $(C \mathrm{t})$.

airway and the tissues, characterized by a resistance $(R \mathrm{p})$ and a compliance $(C \mathrm{t})$. The second compartment, in parallel with the first, is the pathway corresponding to airway walls expansion; airway wall properties are lumped and also characterized by a resistance $(R \mathrm{~b})$ and a compliance $(\mathrm{Cb})$. At low frequencies, the impedance is dominated by the compliances and, because airway walls are much stiffer than the parenchyma $(C b<<C t)$, they influence the impedance very little. As the frequency increases, the impedance depends less on the compliances and increasingly on the resistances. Normally, however, $R \mathrm{p}$ is very small, and it is likely that airway walls still have little influence on the impedance at frequencies below $20-30 \mathrm{~Hz}$. In contrast, when $R \mathrm{p}$ is very much increased, as during the expiratory phase when EFL is present, the high frequency impedance of the airway wall may become much lower than that of the peripheral lung, so that the impedance measured may reflect almost exclusively the properties of that shunt pathway.

In other words, when EFL is present, Im may represent mainly lung and chest wall properties during the inspiratory phase, but airway walls elastic properties during the expiratory phase. In the two examples shown in table $3, C \mathrm{~b} / C \mathrm{t}=0.1$, which is not unreasonable [20]. In the first example, $R \mathrm{~b}$ is assumed to be nil (purely elastic airway walls), whilst in the second it is equal to 20 $\mathrm{hPa} \cdot \mathrm{s} \cdot \mathrm{L}^{-1}$. In both instances, increasing $R \mathrm{p}$ from 20 to $1,000 \mathrm{hPa} \cdot \mathrm{s} \cdot \mathrm{L}^{-1}$, which is a way to simulate EFL, decreases Im markedly. In contrast, $R$ e decreases in the first instance and increases in the second; therefore, a variable airway wall resistance could account for the apparently inconsistent variations of $R$ e observed in this study. The four-coefficient model of figure 4 , however, even with phasic variations of $R \mathrm{p}$, is a very crude representa-

Table 3. - Impedance of the two-compartment model at $15 \mathrm{~Hz}$

\begin{tabular}{rccccc}
\hline $\begin{array}{c}R \mathrm{p} \\
\mathrm{hPa} \cdot \mathrm{s} \cdot \mathrm{L}^{-1}\end{array}$ & $\begin{array}{c}C \mathrm{t} \\
\mathrm{L} \cdot \mathrm{hPa} \mathrm{Pa}^{-1}\end{array}$ & $\begin{array}{c}R \mathrm{~b} \\
\mathrm{hPa} \cdot \mathrm{s} \cdot \mathrm{L}^{-1}\end{array}$ & $\begin{array}{c}C \mathrm{~b} \\
\mathrm{~L} \cdot \mathrm{hPa}{ }^{-1}\end{array}$ & $\begin{array}{c}\mathrm{Re} \\
\mathrm{hPa} \cdot \mathrm{s} \cdot \mathrm{L}^{-1}\end{array}$ & $\begin{array}{c}\mathrm{Im} \\
\mathrm{hPa} \cdot \mathrm{s} \cdot \mathrm{L}^{-1}\end{array}$ \\
\hline 20 & 0.003 & 0 & 0.0003 & 13.1 & -9.9 \\
1000 & 0.003 & 0 & 0.0003 & 1.2 & -35.1 \\
20 & 0.003 & 20 & 0.0003 & 13.2 & -6.6 \\
1000 & 0.003 & 20 & 0.0003 & 20.8 & -33.8 \\
\hline
\end{tabular}

$R$ p: peripheral resistance of airways and tissue; $R \mathrm{~b}$ : airway wall resistance; Re: real part of impedance; Im: imaginary part of impedance; $C$ : peripheral airways and tissue compliance; $C \mathrm{~b}$ : airway wall compliance. tion of the mechanical situation during EFL. It neglects, for instance, the serial resistance of upper airways, which may also vary during the respiratory cycle and depend upon the EP. The above interpretation of the variable response of $R \mathrm{e}$ to EFL is, therefore, rather speculative.

In our experimental conditions, $\mathrm{D}(\mathrm{Im})$ with a threshold of $50 \%$ appeared to have a $100 \%$ specificity for detecting EFL. One must wonder, however, whether large phasic variations of Im may occur in situations other than EFL. In terms of the usual resistance-compliance-inertance model, a decreased Im may only result from a decreased respiratory inertance $(I \mathrm{rs})$ or from a decreased compliance. Conceivably Irs, which is located mainly in the large airways [21], may be lower during the expiratory phase if the upper airways are collapsed during inspiration. This, however, could not happen in artificially-ventilated subjects. $C$ t may vary with lung volume [13], but this would provoke symmetrical variations of Im during the two phases, in contrast to the exclusively expiratory variations seen in EFL. On the other hand, sequential airway closure during expiration, with opening of all closed airways at the very beginning of inspiration, could provoke the Im pattern observed during EFL. In this unlikely situation, $R$ e would probably follow a similar pattern. It is clear, however, that our approach cannot distinguish between situations which have roughly the same effect on the overall airway patency.

Although the sensitivity of $\mathrm{D}(\mathrm{Im})$ to EFL appeared to be extremely good with the selected threshold, false negatives were seen in two out of 45 instances. As already mentioned, EFL occurred in the very last part of the expiration in those two instances. Another reason for false negatives may be the normalization of $\mathrm{D}(\mathrm{Im})$ used in this study. As Im could as well be positive, negative or nil, depending on the frequency and mechanical properties of the subject, its changes could not be expressed as a percentage of its mean inspiratory value. This is why we related them to the inspiratory impedance modulus (Equation 2), which is always positive. A drawback of that normalization is that, for a given change in $\mathrm{Im}, \mathrm{D}(\mathrm{Im})$ will be algebraically smaller if the inspiratory resistance is large. This was the case in one of the two instances where $R$ e had the unusually high value of $71 \mathrm{hPa} \cdot \mathrm{s} \cdot \mathrm{L}^{-1}$. An alternative, which could increase the sensitivity, would be to consider the absolute value of the change; the threshold, however, would have to be adapted to the subject's body size and condition.

The frequency of $15 \mathrm{~Hz}$ chosen in this study to measure respiratory impedance represents a compromise between conflicting requirements. On the one hand, we had previously observed in patients that the phasic changes in Im decreased with increasing frequency [12]. This is consistent with our interpretation terms of the model shown in figure 7 . On the other hand, the frequency had to be large enough to avoid the main harmonics of the breathing signals and to provide a good time resolution for following the course of impedance during the respiratory cycle.

To summarize our findings, we have observed in mechanical analogues and in rabbits that EFL induced by lowering the expiratory pressure is responsible for systematic phasic variations in the imaginary part of respiratory impedance. The study suggests that the latter may 

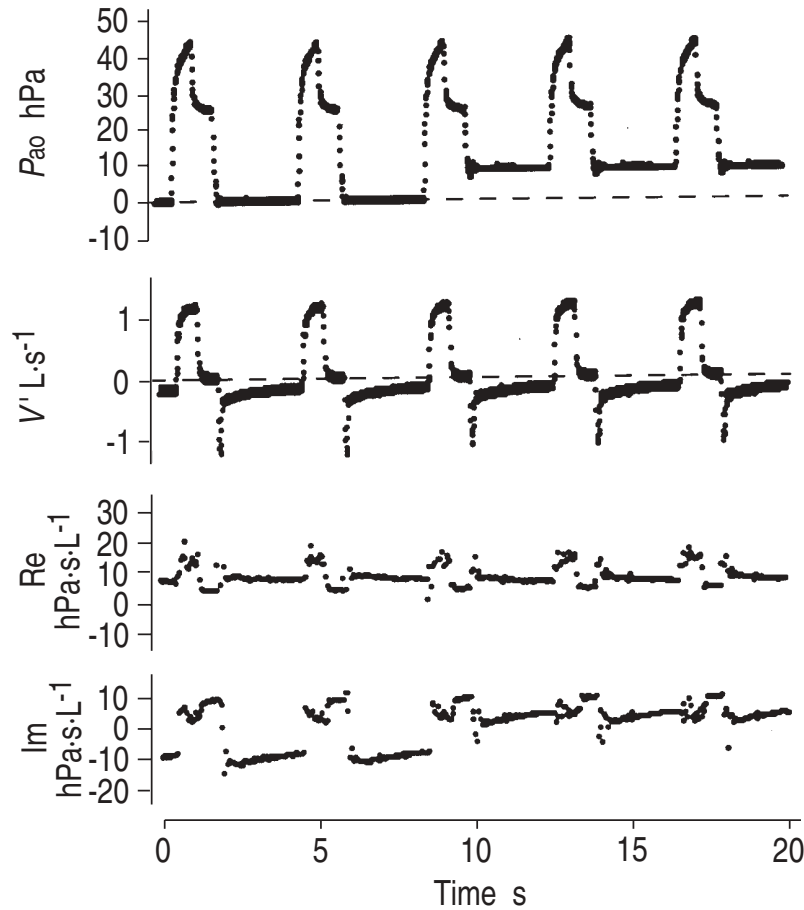

Fig. 8. - Record of airway opening pressure $(P$ ao $)$, flow $\left(V^{\prime}\right)$, real $(\mathrm{Re})$ and imaginary $(\mathrm{Im})$ part of impedance obtained in a mechanicallyventilated patient with severe airway obstruction. Increasing the positive end-expiratory pressure (PEEP) from 0 to $8 \mathrm{hPa}$ almost completely suppresses the phasic variations of $\mathrm{Im}$.

constitute a sensitive and specific index to detect the occurrence of EFL during mechanical ventilation. The method is noninvasive, and, in contrast to methods based on varying the expiratory load [2,9-11], does not require any intervention on the respirator or on the expiratory circuit. It is, therefore, quite suitable for continuous and automatic monitoring of mechanically-ventilated patients. Whilst this work was stimulated by observations made in such patients [12], it remains to be demonstrated, using some reference method, that $\mathrm{D}(\mathrm{Im})$ is, in clinical situations, a sensitive and specific index to detect EFL as seen in this experimental study. That such may be the case is supported by the observation made in a patient with severe airway obstruction and acute respiratory failure (fig. 8): in this patient, who presented large expiratory flow transients, suggestive of expiratory flow limitation [2], accompanied by phasic variations in Im, raising the end-expiratory pressure from zero to $8 \mathrm{hPa}$, slightly decreased the amplitude of the flow transients and almost completely suppressed the decrease of Im during the expiratory phases.

Acknowledgements: The authors are grateful to $\mathrm{P}$ Ulmer for editing, the manuscript and to M.C. Rohrer for the illustrations. The fellowship of M.V. was supported, in part, by a grant from the Scientific Service of the French Embassy in Greece.

\section{References}

1. Pepe PE, Marini JJ. Occult positive end-expiratory pressure in mechanically-ventilated patients with airflow obstruction: the auto-PEEP effect. Am Rev Respir Dis 1982; 126: 166-170.
2. Gottfried SB, Rossi A, Higgs BD, et al. Noninvasive determination of respiratory system mechanics during mechanical ventilation for acute respiratory failure. Am Rev Respir Dis 1985; 131: 414-420.

3. Gay PC, Rodarte JR, Tayyab M, Hubmayr RD. Evaluation of bronchodilator responsiveness in mechanically-ventilated patients. Am Rev Respir Dis 1987; 136: 880-885.

4. Derenne JPh, Fleury B, Pariente R. Acute respiratory failure of chronic obstructive pulmonary disease. Am Rev Respir Dis 1988; 138: 1006-1033.

5. Gay PC, Rodarte JR, Hubmayr RD. The effects of positive expiratory pressure on isovolume flow and dynamic hyperinflation in patients receiving mechanical ventilation. Am Rev Respir Dis 1989; 139: 621-626.

6. Van den Berg B, Stam H, Bogaard JM. Effects of PEEP on respiratory mechanics in patients with COPD on mechanical ventilation. Eur Respir J 1991; 4: 561-567.

7. Milic-Emili J, Gottfried SB, Rossi A. Dynamic hyperinflation: intrinsic PEEP and its ramifications in patients with respiratory failure. In: Vincent $\mathrm{JL}$, ed. Intensive Care Medicine. 1987; pp. 192-198.

8. Smith TC, Marini JJ. Impact of PEEP on lung mechanics and work of breathing in severe airflow obstruction. J Appl Physiol 1988; 65: 1488-1499.

9. Rossi A, Brandolese R, Milic-Emili J, Gottfried SB. The role of PEEP in patients with chronic obstructive pulmonary disease during assisted ventilation. Eur Respir $J$ 1990; 3: 818-822.

10. Valta P, Corbeil C, Lavoie A, et al. Detection of expiratory flow limitation during mechanical ventilation. Am J Respir Crit Care Med 1994; 150: 1311-1317.

11. Kimball WR, Leith DE, Robins AG. Dynamic hyperinflation and ventilator dependence in chronic obstructive pulmonary disease. Am Rev Respir Dis 1982; 126: 991-995.

12. Peslin R, Felicio da Silva J, Duvivier C, Chabot F. Respiratory mechanics studied by forced oscillations during artificial ventilation. Eur Respir J 1993; 6: 772-784.

13. Peslin R, Saunier C, Duvivier C, Marchand M. Analysis of low-frequency lung impedance in rabbits with nonlinear models. J Appl Physiol 1995; 79: 771-780.

14. Duvivier C, Peslin R, Gallina C. An incremental method to assess the linearity of gas flow meters: application to Fleisch pneumotachographs. Eur Respir J 1988; 1: 661-665.

15. Uhl RR, Lewis FJ. Digital computer calculation of human pulmonary mechanics using a least square fit technique. Comput Biomed Res 1974; 7: 489-495.

16. Peslin R, Morinet-Lambert J, Duvivier C. Etude de la réponse en fréquence de pneumotachographes. Bull Eur Physiopathol Respir 1972; 8: 1363-1376.

17. Michaelson ED, Grassman ED, Peters WR. Pulmonary mechanics by spectral analysis of forced random noise. J Clin Invest 1975; 56: 1210-1230.

18. Peslin R. Methods for measuring total respiratory impedance by forced oscillations. Bull Eur Physiopathol Respir 1986; 22: 621-631.

19. Duvivier C, Peslin R, Wendling F, et al. Mesure de l'impédance thoraco-pulmonaire par la méthode des oscillations forcées. Présentation d'un appareil. Innov Tech Biol Med 1990; 11: 382-399.

20. Mead J. Contribution of compliance of airways to frequency-dependent behavior of lungs. J Appl Physiol 1969; 26: 670-673.

21. Oostveen E, Peslin R, Duvivier C, Rotger M, Mead J. Airways impedance during single breaths of foreign gases. J Appl Physiol 1991; 71: 1813-1821. 